\title{
Hydrazine and substituted hydrazines as corrosion inhibitors for lead in acetic acid
}

\author{
S. SANKARAPAPAVINASAM The effect of hydrazine (Hy) and substituted hydrazines (phenyl hydrazine (PHy), \\ F. PUSHPANADEN \\ M. F. AHMED \\ 2,4-dinitrophenyl hydrazine (2,4-DNPHy), 4-nitrobenzoyl hydrazine (4-NBHy), and \\ tosyl hydrazine (THy)) on the corrosion of lead in acetic acid has been investigated. The \\ inhibitive efficiency ranking of these compounds from both weight loss and polarisation \\ measurements was found to be THy $\geqslant 4-N B H y \gg H y>P H y>2,4-D N P H y$. The drift \\ of free corrosion potential to more noble values and the increase in anodic overpotential \\ without any change in Tafel slope in the presence of inhibitors suggest that the inhibitors \\ retard the corrosion process by blocking anodic reaction sites. The relative inhibitive \\ efficiency of these compounds is explained on the basis of structure dependent electron \\ donor properties.
}

Manuscript received 28 March 1988; in final form 11 August 1988. The authors are in the Department of Chemistry, Central College, Bangalore University, Bangalore 560001, India.

\section{INTRODUCTION}

The use of nitrogen containing compounds as corrosion inhibitors is widespread. These compounds can bind to metal surfaces by electron transfer to form a coordinated bond and hence lead to effective inhibition. ${ }^{1}$ The strength of bonding and hence the extent of inhibition is dependent on the nature of the functional group and the structure of the remainder of the inhibitor molecule. Hydrazine and substituted hydrazines have been used as effective corrosion inhibitors for copper ${ }^{2,3}$ and aluminium ${ }^{4}$ in acid media and for mild steel ${ }^{5}$ in an alkaline medium; however, a systematic study of the use of hydrazines as inhibitors is lacking. In the present study the effect of hydrazine (Hy), phenyl hydrazine (PHy), 2,4-dinitrophenyl hydrazine (2,4-DNPHy), paranitrobenzoyl hydrazine (4-NBHy), and tosyl hydrazine (THy) as inhibitors for corrosion of lead in acetic acid has been investigated. Lead is highly soluble in acetic acid and no protective film is formed. This is helpful in establishing accurately the effect of substituents on the inhibitive efficiency of hydrazine. Further, very little work has been performed ${ }^{6}$ on the use of amines as inhibitors for the corrosion of lead in aggressive acidic media, hence the present study was undertaken.

\section{EXPERIMENTAL}

AnalaR grade hydrazine (as hydrate), phenyl hydrazine, and 2,4-dinitrophenyl hydrazine were used in the experiments. Tosyl hydrazine and paranitrobenzoyl hydrazine were prepared, purified, and characterised by nuclear magnetic resonance before use.

The lead samples were prepared from rectangular pieces of pure lead by covering all but one $10 \times 10 \mathrm{~mm}$ portion with lacquer as insulation from the corroding medium. The surface to be exposed was mechanically polished with emery paper up to $4 / 0$ grade, using alcohol as lubricant. After mechanical polishing the specimens were degreased, activated in $1: 1 \mathrm{HNO}_{3}$, washed thoroughly with distilled water, and then exposed to the aerated corroding medium. Corrosion rates were calculated by determining lead present in the solution as light-brown lead sulphide (by bubbling hydrogen sulphide in the presence of sucrose solution) spectrophotometrically (430 $\mathrm{nm}$ absorption).

The polarisation studies were carried out potentiostatically under aerated and stirred conditions using a Tacussel PRT 10-05L potentiostat and employing a three electrode cell assembly. A saturated calomel electrode and a platinum electrode were used as reference and auxillary electrodes respectively. All measurements were carried out at $303 \pm 1 \mathrm{~K}$ unless otherwise specified.

\section{RESULTS}

\section{Weight loss measurements}

The lead samples were exposed for $5 \mathrm{~h}$ in $0.1 \mathrm{M}$ acetic acid, both without additions and containing various concentrations $\left(10^{-9}-10^{-1} \mathrm{M}\right)$ inhibitor. From the calculated corrosion rates the inhibitive efficiency $P(\%)$ and surface coverage $\theta$ of each inhibitor at each concentration were calculated using the equations

$$
\begin{aligned}
& P=100\left(w_{0}-w\right) / w_{0} \\
& \theta=\left(w_{0}-w\right) / w_{0}
\end{aligned}
$$

where $w_{0}$ and $w$ are the weight losses in the absence and presence of inhibitor respectively.

As can be seen from Fig. 1, weight loss varied linearly with immersion period in both the presence and absence of inhibitors. Values of $P$ for various concentrations of the inhibitors are given in Table 1, from which it is evident that the efficiency ranking is $\mathrm{THy} \geqslant 4-\mathrm{NBHy} \gg \mathrm{Hy}>$ PHy $>2,4-$ DNPHy. An optimum value of $\sim 90 \%$ is

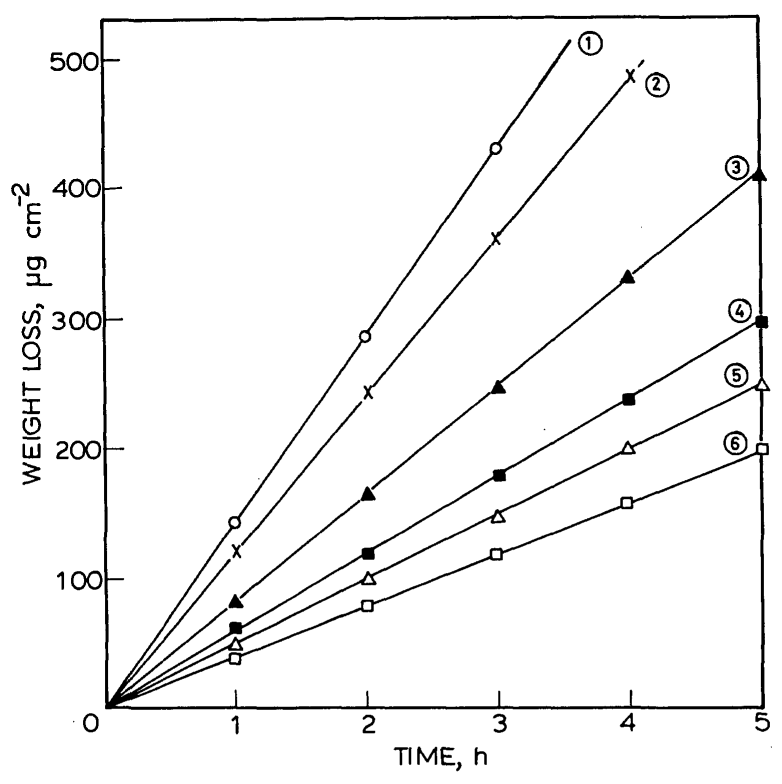

1: no additions; $2: 5 \times 10^{-4} \mathrm{M} 2,4-\mathrm{DNPHy} ; 3: 10^{-1} \mathrm{M}$ PHy; $4: 10^{-1} \mathrm{M}$ Hy; 5: $10^{-1} \mathrm{M}$ 4-NBHy; 6: $5 \times 10^{-6} \mathrm{M}$ THy

1 Variation of weight loss of lead with immersion time in $0 \cdot 1 M$ acetic acid containing various inhibitor additions at $303 \mathrm{~K}$ 
Table 1 Inhibitive efficiency determined from weight loss $(P)$ and polarisation $\left(P^{\prime}\right)$ measurements in $0 \cdot 1 \mathrm{M}$ acetic acid at $303 \mathrm{~K}$ as function of inhibitor concentration

\begin{tabular}{|c|c|c|c|c|c|c|c|c|c|c|}
\hline \multirow{2}{*}{$\begin{array}{l}\text { Inhibitor } \\
\text { conc., } \mathrm{M}\end{array}$} & \multicolumn{2}{|l|}{ THy } & \multicolumn{2}{|c|}{ 4-NBHy } & \multicolumn{2}{|l|}{$\mathrm{Hy}$} & \multicolumn{2}{|l|}{ PHy } & \multicolumn{2}{|c|}{ 2,4-DNPHy } \\
\hline & $P, \%$ & $P^{\prime}, \%$ & $P, \%$ & $P^{\prime}, \%$ & $P, \%$ & $P^{\prime}, \%$ & $P, \%$ & $P^{\prime}, \%$ & $P, \%$ & $P^{\prime}, \%$ \\
\hline $1 \times 10^{-9}$ & $18 \cdot 4$ & $19 \cdot 1$ & $\cdots$ & $\ldots$ & $\ldots$ & $\ldots$ & $\cdots$ & $\ldots$ & $\ldots$ & $\ldots$ \\
\hline $5 \times 10^{-9}$ & $42 \cdot 5$ & $\ldots$ & $14 \cdot 9$ & $\ldots$ & $\ldots$ & $\ldots$ & $\ldots$ & $\ldots$ & $\ldots$ & $\cdots$ \\
\hline $1 \times 10^{-8}$ & $50 \cdot 6$ & $40 \cdot 6$ & $31 \cdot 0$ & $34 \cdot 6$ & $\ldots$ & $\ldots$ & $\ldots$ & $\ldots$ & $\ldots$ & $\ldots$ \\
\hline $5 \times 10^{-8}$ & $54 \cdot 0$ & $\ldots$ & $46 \cdot 0$ & $\ldots$ & $\ldots$ & $\therefore$ & $\ldots$ & $\ldots$ & $\ldots$ & $\ldots$ \\
\hline $1 \times 10^{-7}$ & $57 \cdot 5$ & $51 \cdot 2$ & $50 \cdot 6$ & $52 \cdot 1$ & $\ldots$ & $\ldots$ & $\ldots$ & $\ldots$ & $\ldots$ & $\ldots$ \\
\hline $5 \times 10^{-7}$ & $59 \cdot 8$ & $\ldots$ & $51 \cdot 7$ & $\ldots$ & $\ldots$ & $\ldots$ & $\ldots$ & $\ldots$ & $\ldots$ & $\ldots$ \\
\hline $1 \times 10^{-6}$ & $65 \cdot 5$ & $62 \cdot 0$ & $55 \cdot 2$ & $56 \cdot 4$ & $\ldots$ & $\ldots$ & $\ldots$ & $\ldots$ & $\ldots$ & $\ldots$ \\
\hline $5 \times 10^{-6}$ & $72 \cdot 4$ & $\ldots$ & $64 \cdot 4$ & $\ldots$ & $8 \cdot 0$ & $\ldots$ & $\ldots$ & $\ldots$ & $\ldots$ & $\ldots$ \\
\hline $1 \times 10^{-5}$ & $88 \cdot 5$ & $76 \cdot 4$ & $77 \cdot 0$ & $75 \cdot 0$ & $17 \cdot 2$ & $19 \cdot 4$ & $2 \cdot 3$ & $4 \cdot 6$ & $\ldots$ & $\ldots$ \\
\hline $5 \times 10^{-5}$ & $92 \cdot 0$ & $\ldots$ & $82 \cdot 8$ & $\ldots$ & $19 \cdot 5$ & $\ldots$ & $9 \cdot 2$ & $\ldots$ & 6.9 & $\ldots$ \\
\hline $1 \times 10^{-4}$ & $94 \cdot 3$ & $90 \cdot 1$ & $88 \cdot 5$ & $84 \cdot 0$ & $25 \cdot 3$ & $25 \cdot 4$ & $13 \cdot 8$ & $14 \cdot 0$ & $11 \cdot 5$ & $15 \cdot 0$ \\
\hline $5 \times 10^{-4}$ & $94 \cdot 3$ & $90 \cdot 1$ & $88 \cdot 5$ & $84 \cdot 0$ & $27 \cdot 6$ & $\ldots$ & $18 \cdot 4$ & $\ldots$ & $14 \cdot 9$ & $17 \cdot 2$ \\
\hline $1 \times 10^{-3}$ & $94 \cdot 3$ & $90 \cdot 1$ & $88 \cdot 5$ & $84 \cdot 0$ & $31 \cdot 0$ & $34 \cdot 0$ & $21 \cdot 8$ & $20 \cdot 2$ & $14 \cdot 9$ & $17 \cdot 2$ \\
\hline $5 \times 10^{-3}$ & $94 \cdot 3$ & $90 \cdot 1$ & $88 \cdot 5$ & $84 \cdot 0$ & $34 \cdot 5$ & $\ldots$ & $24 \cdot 1$ & $\ldots$ & 14.9 & $17 \cdot 2$ \\
\hline $1 \times 10^{-2}$ & $94 \cdot 3$ & $90 \cdot 1$ & $88 \cdot 5$ & $84 \cdot 0$ & $40 \cdot 2$ & $44 \cdot 0$ & $26 \cdot 4$ & $25 \cdot 3$ & $14 \cdot 9$ & $17 \cdot 2$ \\
\hline $5 \times 10^{-2}$ & $94 \cdot 3$ & $90 \cdot 1$ & $88 \cdot 5$ & $84 \cdot 0$ & $46 \cdot 0$ & $\ldots$ & $28 \cdot 7$ & $\ldots$ & $14 \cdot 9$ & $17 \cdot 2$ \\
\hline $1 \times 10^{-1}$ & $94 \cdot 3$ & $90 \cdot 1$ & $88 \cdot 5$ & $84 \cdot 0$ & $59 \cdot 8$ & 63.0 & $43 \cdot 7$ & $40 \cdot 4$ & $14 \cdot 9$ & $17 \cdot 2$ \\
\hline $5 \times 10^{-1}$ & $94 \cdot 3$ & $90 \cdot 1$ & $88 \cdot 5$ & $84 \cdot 0$ & $59 \cdot 8$ & 63.0 & $43 \cdot 7$ & $40 \cdot 4$ & $14 \cdot 9$ & $17 \cdot 2$ \\
\hline
\end{tabular}

achieved at a concentration of $10^{-4} \mathrm{M}$ with $\mathrm{THy}$ and 4- $\mathrm{NBHy}$, a value of $60 \%$ at $10^{-1} \mathrm{M}$ with $\mathrm{Hy}$, a value of $40 \%$ at $10^{-1} \mathrm{M}$ with $\mathrm{PHy}$, and a value of $15 \%$ at $5 \times 10^{-4} \mathrm{M}$ with 2,4-DNPHy.

A plot of $\theta$ versus $\log c$ (where $c$ is the concentration of inhibitor) followed an S type curve (Fig. 2) characteristic of the Frumkin adsorption isotherm ${ }^{7}$

$$
[\theta /(1-\theta)] \exp (-f \theta)=K c
$$

The equilibrium constant $K$ is given by

$$
K=\exp \left(-\Delta G_{\text {ads }}^{0} / R T\right)
$$

where $R$ is the universal gas constant and $T$ absolute temperature. The free energies of adsorption $\Delta G_{\text {ads }}^{0}$ calculated using this isotherm are given in Table 2.

The dissolution rate of lead was also determined in different concentrations $(0 \cdot 1-10 \mathrm{M})$ of acetic acid at constant concentration of each inhibitor. The corrosion rate increased with increasing concentration of acid (plain or inhibited), whereas the values of $P$ decreased (Table 3 ).

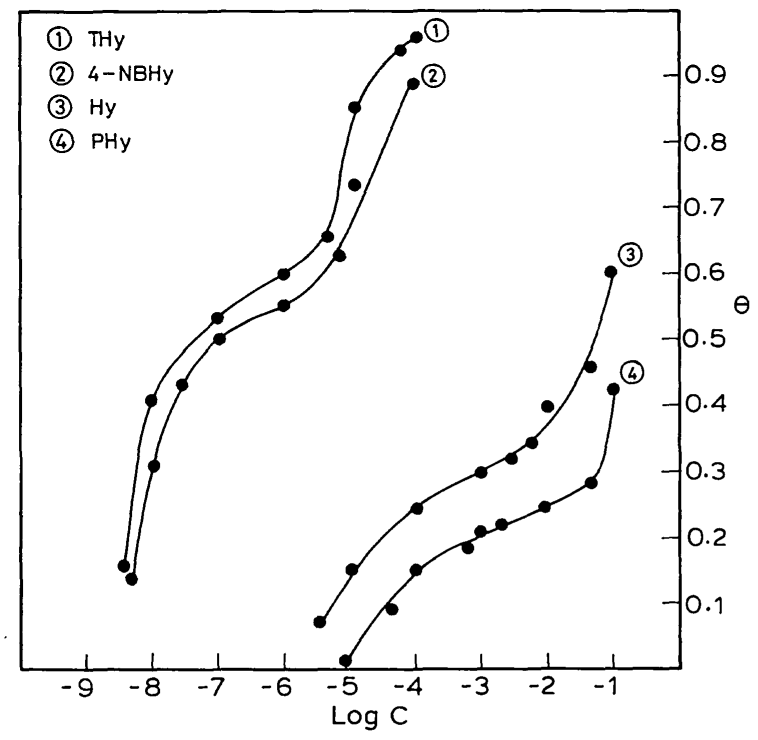

1: THy; 2: 4-NBHy; 3: Hy; 4: PHy

2 Frumkin adsorption isotherms for inhibitors on lead in stirred $0 \cdot 1 \mathrm{M}$ acetic acid at $303 \mathrm{~K}$
The effect of temperature in the range $293-323 \mathrm{~K}$ on corrosion rate was also studied. The corrosion rate increased with increasing temperature in plain acetic acid and in the acid containing 2,4-DNPHy but decreased with increasing temperature in acetic acid containing $\mathrm{Hy}, \mathrm{PHy}$, THy, and 4-NBHy. However the values of $P$ increased with increasing temperature for all the inhibitors (Table 4). The energies of activation $E_{\mathrm{a}}$ for the corrosion process in plain and inhibited acid were evaluated from the slopes of $\log$ (corrosion rate) versus $T^{-1}$ Arrhenius plots (Fig. 3). The values obtained are given in Table 2 together with heats of adsorption $\Delta H_{\mathrm{ads}}^{0}$ calculated from the Frumkin isotherm.

Free corrosion potentials were recorded once steady values had been attained; the results are given in Table 5 . The free corrosion potentials shifted to more noble values in the presence of inhibitors and the extent of this shift was found to be a function of the nature and concentration of the inhibitor.

\section{Polarisation measurements}

Potentiostatic anodic and cathodic polarisation scans were carried out in stirred $0 \cdot 1 \mathrm{M}$ acetic acid and Tafel plots constructed. Significant polarisation was observed in the anodic direction and negligible polarisation in the cathodic direction. The cathodic Tafel plots were not altered in any way by the presence of inhibitor, while the anodic plots were shifted to higher potentials without any appreciable change in slope (Fig. 4). The anodic Tafel plots were extrapolated to the free corrosion potentials and exchange

Table 2 Free energy of adsorption $\Delta G_{\text {ads }}^{\text {, }}$ heat of adsorption $\Delta H_{\mathrm{ads}}^{\mathrm{o}}$, and activation energy $E_{\mathrm{a}}$ for various inhibitors on lead in acetic acid: $E_{\mathrm{a}}$ in uninhibited acid $=23.9 \mathrm{~kJ} \mathrm{~mol}^{-1}$

\begin{tabular}{llll}
\hline Inhibitor & $\begin{array}{l}E_{\mathrm{a}}, \\
\mathrm{kJ} \mathrm{mol}^{-1}\end{array}$ & $\begin{array}{l}\Delta H_{\mathrm{ads}}^{\mathrm{o}}, \\
\mathrm{kJ} \mathrm{mol}^{-1}\end{array}$ & $\begin{array}{l}\Delta G_{\mathrm{ads}}^{\mathrm{o}} \\
\mathrm{kJ} \mathrm{mol}^{-1}\end{array}$ \\
\hline THy & $-5 \cdot 2$ & $28 \cdot 4$ & $-27 \cdot 7$ \\
4-NBHy & $-4 \cdot 3$ & $26 \cdot 1$ & $-23 \cdot 5$ \\
Hy & $-6 \cdot 4$ & $22 \cdot 4$ & $-23 \cdot 6$ \\
PHy & $-4 \cdot 8$ & $21 \cdot 2$ & $-19 \cdot 9$ \\
2,4-DNPHy & $+6 \cdot 4$ & $25 \cdot 2$ & $-19 \cdot 5$ \\
\hline
\end{tabular}


Table 3 Variation of corrosion rate and inhibitive efficiency $P$ with acetic acid concentration at $303 \mathrm{~K}$ containing various inhibitor additions

\begin{tabular}{|c|c|c|c|c|c|c|}
\hline \multirow[b]{2}{*}{ Acid conc., M } & \multicolumn{6}{|c|}{ Corrosion rate, $\mu \mathrm{g} \mathrm{cm}^{-2} \mathrm{~h}^{-1}(P, \%)$} \\
\hline & No addition & $5 \times 10^{-6} \mathrm{M}$ THy & $5 \times 10^{-6} \mathrm{M} 4-\mathrm{NBHy}$ & $10^{-1} \mathrm{M} \mathrm{Hy}$ & $10^{-1} \mathrm{M} \mathrm{PHy}$ & $5 \times 10^{-4}$ M 2,4-DNPHy \\
\hline $0 \cdot 1$ & 137 & $45 \cdot 8(66 \cdot 5)$ & $60.4(55.8)$ & $62 \cdot 5(54 \cdot 3)$ & $87 \cdot 5(36 \cdot 1)$ & $125(8 \cdot 6)$ \\
\hline 1.0 & 160 & $54 \cdot 2(66 \cdot 2)$ & $77 \cdot 1(51 \cdot 9)$ & $81 \cdot 2(49 \cdot 4)$ & $104(35 \cdot 1)$ & * $(0)$ \\
\hline $2 \cdot 0$ & 175 & $75 \cdot 0(57 \cdot 1)$ & $93.7(46 \cdot 5)$ & $97.9(44 \cdot 1)$ & $125(28 \cdot 6)$ & * $(0)$ \\
\hline 3.0 & 206 & $95.8(53.6)$ & $125(39.4)$ & $127(38.4)$ & $158(23 \cdot 2)$ & * $(0)$ \\
\hline $4 \cdot 0$ & 269 & $146(45 \cdot 7)$ & $177(34 \cdot 1)$ & $185(31 \cdot 0)$ & $227(15 \cdot 5)$ & * $(0)$ \\
\hline $5 \cdot 0$ & 319 & $208(34 \cdot 6)$ & $220(30 \cdot 7)$ & $250(21 \cdot 6)$ & $277(13 \cdot 1)$ & * (0) \\
\hline $6 \cdot 0$ & 348 & $229(34 \cdot 1)$ & $264(24 \cdot 0)$ & $310(10 \cdot 8)$ & $333(4 \cdot 2)$ & * (0) \\
\hline $7 \cdot 0$ & 362 & $306(15 \cdot 5)$ & $319(12 \cdot 1)$ & * $(0)$ & $*(0)$ & * (0) \\
\hline $10 \cdot 0$ & 406 & $*(0)$ & $*(0)$ & * $(0)$ & * (0) & $*(0)$ \\
\hline
\end{tabular}

* Optical density value almost identical with that for uninhibited acid.

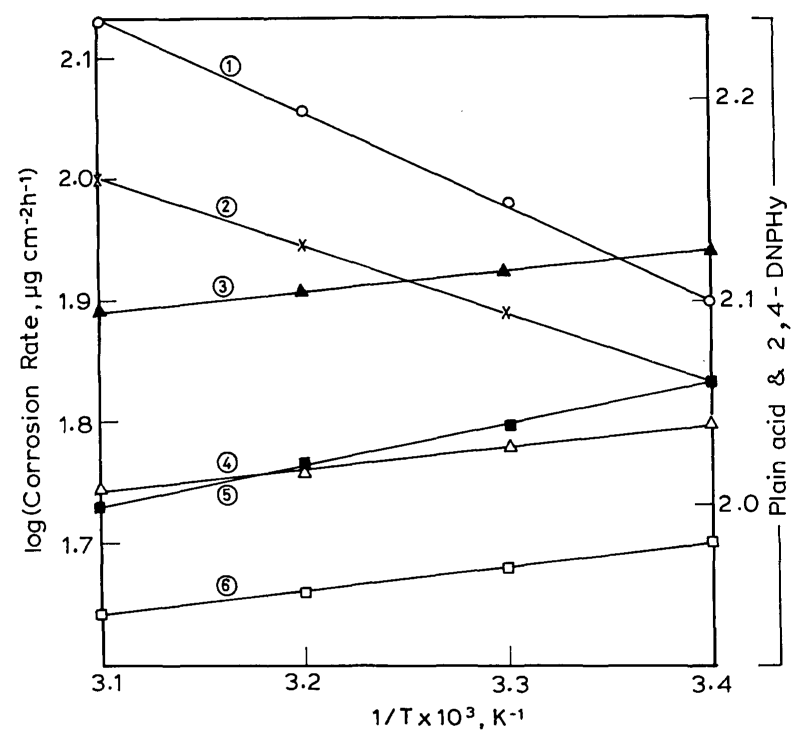

1: no additions; 2: 2,4-DNPHy; 3: PHy; 4: 4-NBHy; 5: Hy; 6: THy

3 Arrhenius plots for corrosion of lead in $0 \cdot 1 \mathrm{M}$ acetic acid containing various inhibitor additions

current densities determined. Inhibitive efficiencies $P^{\prime}$ were calculated using the relation

$$
P^{\prime}=\left(i_{0}-i\right) / i_{0}
$$

where $i_{0}$ and $i$ are the exchange current densities in the absence and presence of inhibitors respectively. The values of $P^{\prime}$ were found to be in good agreement with those of $P$ obtained by the weight loss method (Table 1).

\section{DISCUSSION}

The corrosion of lead in aerated acidic solutions is a result of the partial reactions anodic

$$
\mathrm{Pb} \rightarrow \mathrm{Pb}^{2+}+2 \mathrm{e}^{-}
$$

cathodic

$$
\left.\begin{array}{l}
2 \mathrm{H}^{+}+2 \mathrm{e}^{-} \rightarrow \mathrm{H}_{2}(\text { low } \mathrm{pH}) \\
\mathrm{O}_{2}+4 \mathrm{H}^{+}+4 \mathrm{e}^{-} \rightarrow 2 \mathrm{H}_{2} \mathrm{O}(\text { high } \mathrm{pH})
\end{array}\right\}
$$

The linear variation of weight loss with time in plain and inhibited $0 \cdot 1 \mathrm{M}$ acetic acid (Fig. 1) indicates the absence of insoluble surface films during corrosion. In the absence of any pre-existing film, the inhibitors are first adsorbed on to the metal surface and thereafter impede corrosion either by merely blocking the reaction (anodic and cathodic) sites or by altering the course of the anodic and cathodic partial processes (equations (1) and (2)). In the present instance, since the inhibitors caused no change in anodic or cathodic Tafel slopes, the former mechanism is probably operating. ${ }^{1}$ The shift of free corrosion potential to more noble values in the presence of inhibitors (Table 4) is indicative of a predominant blocking of anodic reaction sites. ${ }^{8}$ Since the corrosion of metals is initiated at reaction sites (defects) on the surface, ${ }^{9}$ their blockage impedes corrosion. In such a case an increase in anodic overpotential would be expected in the presence of inhibitors, and the shifts observed in Fig. 4 corroborate this. Hydrazines, being weakly basic, should be present in the protonated state or cationic form in acid solution. Since the potential at the anodic sites is more negative than that at the cathodic sites, adsorption of inhibitor cations is much more likely at anodic sites, as was observed in the present experiments.

Since the inhibitors contain atoms with lone pairs of electrons, electron transfer from the adsorbed inhibitor to the metal surface can occur, resulting in the formation of a coordinated bond, strongly binding the inhibitor molecules to the surface. The large negative free energies of adsorption and the positive heats of adsorption observed in the present case (Table 2) are usually characteristic of

\begin{tabular}{|c|c|c|c|c|c|c|}
\hline \multirow{2}{*}{$\begin{array}{l}\text { Temperature, } \\
\mathrm{K}\end{array}$} & \multirow{2}{*}{$\begin{array}{l}\text { Corrosion rate } \\
\text { in plain acid, } \\
\mu \mathrm{g} \mathrm{cm}^{-2} \mathrm{~h}^{-1}\end{array}$} & \multicolumn{5}{|l|}{$P, \%$} \\
\hline & & THy & 4-NBHy & Hy & PHy & 2,4-DNPHy \\
\hline 293 & 125.0 & $56 \cdot 6$ & $50 \cdot 0$ & $46 \cdot 7$ & $30 \cdot 0$ & $8 \cdot 3$ \\
\hline 303 & $136 \cdot 8$ & $63 \cdot 5$ & 55.8 & $54 \cdot 3$ & $37 \cdot 6$ & 9.9 \\
\hline 313 & $158 \cdot 3$ & $71 \cdot 1$ & $64 \cdot 5$ & 64.5 & $47 \cdot 4$ & $13 \cdot 5$ \\
\hline 323 & $175 \cdot 0$ & $77 \cdot 4$ & 69.0 & $70 \cdot 2$ & 55.9 & $17 \cdot 1$ \\
\hline
\end{tabular}
strong interaction. In addition, the decrease in activation

Table 4 Dependence of inhibitive efficiency $P$ on temperature in $0 \cdot 1 \mathrm{M}$ acetic acid 
Table 5 Variation of free corrosion potential with inhibitor concentration in $0 \cdot 1 \mathrm{M}$ acetic acid at $303 \mathrm{~K}$

\begin{tabular}{|c|c|c|c|c|c|}
\hline \multirow[b]{2}{*}{ Inhibitor conc., $\mathrm{M}$} & \multicolumn{5}{|c|}{ Free corrosion potential, mV(SCE) } \\
\hline & THy & 4-NBHy & Hy & PHy & 2,4-DNPHy \\
\hline 0 & -413 & -413 & -413 & -413 & -413 \\
\hline $10^{-8}$ & -306 & -345 & $\ldots$ & $\ldots$ & $\ldots$ \\
\hline $10^{-7}$ & -269 & -289 & $\ldots$ & $\ldots$ & $\ldots$ \\
\hline $10^{-6}$ & -218 & -244 & $\ldots$ & $\ldots$ & $\ldots$ \\
\hline $10^{-5}$ & -184 & -196 & $\ldots$ & $\ldots$ & $\ldots$ \\
\hline $10^{-4}$ & -100 & -108 & -343 & -401 & -410 \\
\hline $10^{-3}$ & $\cdots$ & $\cdots$ & -270 & -345 & -340 \\
\hline $10^{-2}$ & $\cdots$ & $\cdots$ & -194 & -288 & $\ldots$ \\
\hline $10^{-1}$ & $\cdots$ & $\cdots$ & -114 & -204 & $\ldots$ \\
\hline
\end{tabular}

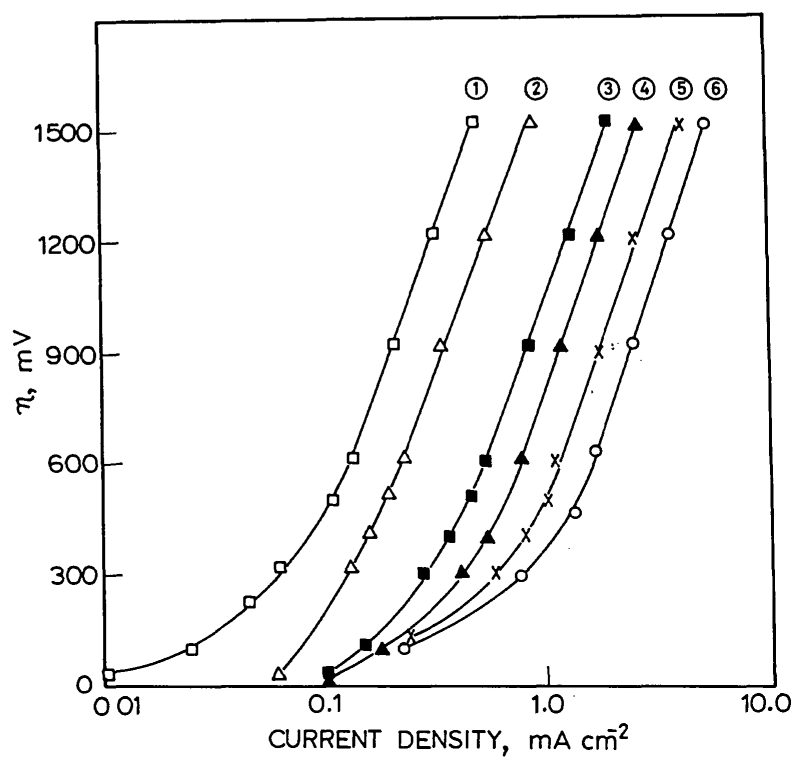

1: $10^{-4} \mathrm{M}$ THy; 2: $10^{-4} \mathrm{M}$ 4-NBHy; $3: 10^{-1} \mathrm{M}$ Hy; 4: $10^{-4} \mathrm{M}$ PHy; 5: $5 \times 10^{-4} \mathrm{M}$ 2,4-DNPHy; 6: no additions

4 Anodic Tafel curves for lead in stirred $0.1 M$ acetic acid containing various inhibitor additions at $303 \mathrm{~K}$

energy in the presence of inhibitors and the increase in $P$ with temperature are suggestive of chemisorption of the inhibitors on to the metal surface. ${ }^{3}$

The decrease of $P$ with increasing concentration of acid can be attributed to the increased tendency of the metal to react with the acid accompanied by vigorous liberation of hydrogen. This may hinder the establishment of adsorption, thus resulting in a decrease of inhibitive efficiency.

The inhibitive efficiency ranking for the compounds studied is:

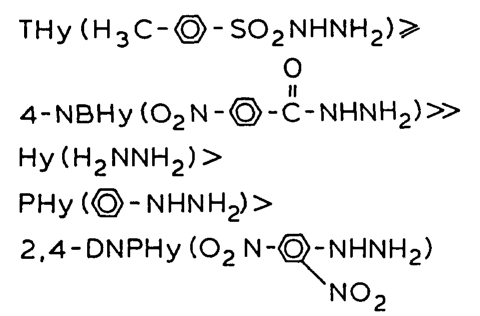

This gradation can be explained in terms of the relative electron donor properties of the anchoring atom and the functional groups. Hy, PHy, and 2,4-DNPHy are anchored on to the metal surface by the nitrogen atom of the $\mathrm{NH}_{2}$ group. The electron density at this nitrogen atom in these inhibitor molecules varies as $\mathrm{Hy}>\mathrm{PHy}>$ 2,4-DNPHy. Since one of the main contributing factors to inhibitive efficiency is the availability of electrons to the anchoring atom, the inhibitive efficiency also varies in the same order. THy and 4-NBHy, on the other hand, have additional electron donor atoms such as the sulphur of the $\mathrm{SO}_{2}$ group in $\mathrm{THy}$ and the oxygen of the $\mathrm{C}=\mathrm{O}$ group in 4-NBHy. It is probable that these molecules are anchored additionally by these respective atoms which would account for the high inhibitive efficiency observed. The greater efficiency of THy compared to 4-NBHy is due to the low electronegativity of sulphur compared to oxygen and also to the presence of the para $\mathrm{CH}_{3}$ group in THy and the para $\mathrm{NO}_{2}$ group in 4-NBHy.

\section{ACKNOWLEDGMENTS}

The authors are grateful to the Department of Science and Technology, Government of India for financial support. They also gratefully acknowledge the kind encouragement given by Professor K. M. Sivanadiah, Head of the Department of Chemistry, Bangalore University, in the pursuit of this research work.

\section{REFERENCES}

1. J. G. N. THOMAS: Proc. Symp. on 'Practical aspects of corrosion inhibition', Teddington, February 1979, National Physical Laboratory.

2. S. SIDDAGANGAPPa, S. M. MAYANNA, and F. PUSHPANADEN: Anticorros. Methods Mater., 1976, 8, 11.

3. I. N. PUTILOVA, S. A. BALEZIN, and v. P. BARANNIK: 'Metallic corrosion inhibitors'; 1960, Oxford, Pergamon.

4. M. H. SHAWKY, Y. A. ELAWADY, A. I. AHMED, and A. O. BAGHLAF: Corros. Sci., 1979, 19, 951.

5. N. C. SUbramanyam, B. S. SHeshadri, and S. M. mayanna: Proc. 10th Int. Conf. on 'Metallic corrosion', Vol. 3, 3007; 1987, New Delhi, Oxford and IBH Publishing Co.

6. A. M. FaWZY, G. H. SEDAHMEd, and A. A. MOHAMmed: Surf. Technol., 1981, 14, (3), 257.

7. A. N. FRUMKIN: $Z$. Phys. Chem., 1925, 116, 466.

8. H. KAESCHE and N. HACKERMAN: J. Electrochem. Soc., 1961, 105, 191.

9. T. P. hOAR and R. D. hOllidaY: J. Appl. Chem., 1953, 3, 502. 